AKUNTABILITAS

Vol. VIII, No. 1, April 2015

P-ISSN: 1979-858X

Halaman $61-77$

\title{
PENGARUH DIMENSI BUDAYA DAN RELIGIUSITAS TERHADAP KECURANGAN PAJAK
}

\author{
Yesi Mutia Basri \\ Universitas Riau
}

\begin{abstract}
This research aims to analyze and get empirical evidence about the effect of dimension of culture (Power Distance, Individualism, uncertainty avoidance, masculinity) and religiouity on tax evasion. Population in this study is individual tax payer listed in KPP Pratama Tampan Pekanbaru. Sampling technic is convenience sampling. From 100 questioners distributed, 6o responden participated. The regression analysis results indicate power distance and masculinity affect have positif effect on tax evasion, but higher religiosity has negatif effect on tax evasion. Finding indicate uncertainty avoidance and individualism have not significant effect on tax evasion.
\end{abstract}

Keywords: Culture, Power Distance, Masculinity, Invidualism, Religiosity And Tax Evasion

\begin{abstract}
ABSTRAK: Penelitian ini bertujuan untuk menganalisis dan mendapatkan bukti empiris tentang pengaruh dimensi budaya (jarak kekuasaan, individualis, ketidakpastian penghindaran, maskulinitas) dan religiusitas terhadap tingkat kecurangan pajak. Populasi penelitian ini adalah wajib pajak individu yang terdaftar di KPP Pratama Tampan Pekanbaru. Teknik sampling yang digunakan convenience sampling. Dari 100 kuesioner didistribusikan 60 responden berpartisipasi. Hasil analisis regresi menunjukkan jarak kekuasaan dan maskulinitas berpengaruh positif pada penggelapan pajak, tetapi religiusitas tinggi memiliki pengaruh negatif pada penggelapan pajak. Hasil penelitian menunjukkan ketidakpastian penghindaran dan individualisme tidak berpengaruh terhadap tingkat kecurangan pajak.
\end{abstract}

Kata kunci: Budaya, Jarak Kekuasaan, Maskulinitas, Invidualisme, Religiusitas Dan Kecurangan Pajak

\footnotetext{
${ }^{1}$ Draft pertama: 10 Januari 2015 ; Revisi: 20 Februari 2015 ; Diterima: 15 Maret 2015

Penulis dapat dikontak melalui: i.yesimutia@yahoo.com
} 


\section{PENDAHULUAN}

Kecurangan pajak sudah menjadi hal yang sangat penting di banyak negara maju dalam jangka waktu yang lama (lihat misalnya, Jackson \& Milliron, dan Amp sejak 1986, \& swingen, dan amp andreoni, 1991. Erard, \& Feinstein, dan amprichardson \& tahun 1998, dan amp; Sawyer. 2001). Namun, banyak penelitian yang telah mengganggu hubungan persahabatan dan budaya (Andreoni et al 1998, 818; lm \& torgler, 2006; Richardson, 2007)

Roth, scholz \& dryden-witte (1989) mengklaim bahwa berbagai budaya yang membentuk sebuah konteks dan interpretasi peristiwa yang dapat mempengaruhi sikap masyarakat terhadap penghindaran pajak. Mereka berargumentasi bahwa berbagai variasi budaya menunjukkan nilai-nilai dan norma perilaku tertentu. Nilai-nilai ini dan norma diungkapkan dan menafsirkan sikap seseorang, bagaimana hubungan sosial mereka sehari-hari yang dapat baik menambah atau mengurangi penghindaran pajak. Banyak penelitian sebelumnya menemukan keragaman dalam penghindaran pajak terjadi karena pola dalam konteks budaya berbeda. Misalnya, strumpel (1969) membandingkan berbagai respon terhadap budaya administrasi perpajakan pada berbagai negara. Dia menekankan pentingnya warisan budaya nasional dalam pemahaman penghindaran pajak. Tittle (1980) menemukan latar belakang budaya secara signifikan terkait dengan kecenderungan menyimpang dari wajib pajak. Coleman \& Freeman (1997) mengamati bahwa kepatuhan sukarela adalah fungsi pajak yang memiliki nilai budaya lingkungan di Australia.

Penelitian terdahulu menemukan black-box yang gagal mengidentifikasi bagaimana dimensi budaya tertentu bisa menjadi terkait dengan penghindaran pajak. Tsakumis, Curatola \& Porcano (2007) menggunakan dimensi budaya Hofstede (1980) untuk menjelaskan penghindaran pajak di seluruh negara. Secara khusus, dimensi budaya power distance, individualisme, uncertainty avoidance, dan maskulinitas, menemukan kajian budaya yang diwakili oleh Hofstede (1980) memberikan kontribusi untuk pemahaman yang lebih baik dari kecurangan pajak secara internasional.Tsakumis et al (2007) menunjukkan bahwa semakin tinggi tingkat power distance dan uncertainty avoidance dan menurunnya tingkat individualisme dan maskulinitas, semakin tinggi adalah tingkat penghindaran pajak di seluruh negara.

Namun demikian kajian empiris antar negara yang dilakukan Tsakumis et al (2007) menimbulkan pertanyaan apakah hasil penelitian mereka tentang budaya dan penghindaran pajak hanya mencerminkan karakteristik yang mendasari data yang digunakan dan oleh karenanya menjadi tidak dapat digeneralisasi. Untuk alasan ini, hasil penelitian mereka harus diuji menggunakan beberapa langkahlangkah dari penghindaran pajak untuk mendapatkan bukti lebih lanjut pada subjek.

Penghindaran pajak Internasional harus diperluas untuk mencakup tambahan variabel terkait dengan hukum, politik, dan lembaga-lembaga keagamaan. Riahi-belkaoiu (2004) dan Tsakumis et al. (2007) membangun sebuah komprehensif model internasional termasuk hukum dari penghindaran pajak, politik, dan variabel agama.

Richardson (2008) juga melakukan kajian penghindaran pajak antar negara dengan menggunakan dimensi budaya Hofstede menunjukkan bahwa tingginya 
level uncertainty Avoidance dan rendahnya level individualisme, penegakan hukum, kepercayaan pada pemerintah dan religiusitas, menyebabkan tingginya kecurangan pajak antar negara.

Penelitian ini bertujuan untuk menguji pengaruh dimensi budaya dan aspek religiusitas wajib pajak terhadap perilaku penghindaran pajak. Penelitian ini menguji wajib pajak orang pribadi yang memiliki berbagai suku budaya serta agama.

\section{KERANGKA TEORI DAN PENGEMBANGAN HIPOTESIS}

\section{Jarak Kekuasaan (Power Distance) dan Kecurangan Pajak}

Jarak kekuasaan berfokus pada tingkat kesetaraan (atau ketidaksetaraan) antara orang-orang di suatu negara. Dalam jarak kekuasaan yang tinggi, ketidaksetaraan kekuasaan dan kekayaan, di mana pemegang kekuasaan berhak untuk mendapatkan hak-hak istimewa (Hofstede, 1980). Oleh karena itu, sistem pajak di negara-negara tersebut cenderung tidak adil dan melindungi sehingga perbedaan pendapatan yang besar di negara-negara tersebut lebih meningkat dengan sistem pajak (Hofstede, 1980). Dalam lingkungan ini, orang cenderung menganggap sistem pajak tidak adil, dan berusaha untuk menghindari pajak penghasilan.

Song \& Yarbrough (1978) juga menemukan adanya hubungan yang negatif, antara $75 \%$ membayar pajak mengklaim bahwa konsep keadilan merupakan"ability-to-pay" yaitu lebih signifikan berhubungan dengan kecurangan pajak. Sebaliknya, di negara-negara jarak kekuasaan rendah, ketidaksetaraan kekuasaan dan kekayaan tidak diperbolehkan untuk berkembang. Bahkan, kesetaraan dan kesempatan bagi semua orang ditekankan (Hofstede, 1980, 122). Oleh karena itu, sistem pajak di negara-negara tersebut cenderung merata, bertujuan mendistribusikan kekayaan dan memastikan bahwa setiap perbedaan pendapatan kecil yang ada dikurangi sistem pajak (Hofstede, 1980, 135). Didalam pengaturan, orang cenderung menganggap sistem pajak yang adil, dan sesuai dengan undang-undang pajak.

Dapat disimpulkan jarak kekuasaan yang ditunjukkan dengaan tingginya kekeuasaan dan kekayaan pada kalangan tertentu menyebabkan masyarakat cenderung untuk melakukan kecurangan pajak. Berdasarkan hal tersebut maka hipotesis dalam penelitian ini adalah:

H1 : Jarak kekuasaan berpengaruh positif terhadap tingkat kecurangan pajak

\section{Individualisme dan Kecurangan Pajak.}

Individualisme berfokus pada sejauh mana suatu negara memperkuat prestasi individu atau kolektif dan interpersonal hubungan. Di negara-negara individualisme tinggi, standar nilai yang sama harus berlaku untuk semua orang (Hofstede, 1980, 235). Ini berarti bahwa aturan dan prosedur yang diterapkan secara universal untuk memastikan ekuitas dan konsistensi (Trompenaars \& Hampden-Turner,1998, 44). Oleh karena itu, sistem pajak di negara-negara tersebut cenderung merata dan sesuai dengan prinsip kemampuan untuk membayar karena undang-undang pajak berlaku bagi orang dengan cara yang sama, sehingga distribusi beban pajak cukup menyebar (Sandford, tahun 2000, 37). 
Dalam pengaturan ini, orang cenderung untuk mematuhi undang-undang pajak karena mereka menganggap sistem pajak yang adil (lihat misalnya, Spicer \& Lundstedt, 1976; Milliron \& Toy, 1988). Sebaliknya, di negara-negarayang individualismenya rendah, standar nilai berbeda untukdalam kelompok dan luar kelompo tertentu (Hofstede, 1980, 235).

Ini berarti bahwa fleksibilitas dalam aturan dan prosedur didorong dalam situasi tertentu (Trompenaars \& Hampden-Turner 1998, 44). Dengan demikian, sistem pajak di negara-negara tersebut cenderung tidak adil dan melanggar prinsip kemampuan untuk membayar mereka karena undang-undang pajak berlaku bagi orang dengan cara yang berbeda, sehingga beban pajak tersebar secara tidak adil (Surrey \& McDaniel, 1985, 89). Dalam lingkungan ini, orang cenderung menghindari pajak pendapatan karena mereka menganggap sistem pajak sebagai tidak adil (lihat misalnya, Memakai \& Headey, 1997). Berdasarkan penelitian terdahulu maka hipotesis penelitian ini adalah:

H2: individualisme berpengaruh negatif terhadap tingkat kecurangan pajak

\section{Ketidakpastian dan Kecurangan Pajak}

Dalam ketidakpastian yang tinggi dan rendahnya tolerasi menyebabkan aturan-banyaknya hukum dan peraturan yang ditulis membantu mengurangi jumlah ketidakpastian dan ambiguitas (Hofstede, 1980). Oleh karena itu, sistem pajak di negara-negara tersebut cenderung menjadi kompleks karena kebutuhan bagi banyak undang-undang perpajakan ditulis dan peraturan untuk mengurangi ketidakpastian dan ambiguitas. Dalam situasi ini, orang cenderung untuk mempertimbangkan sistem pajak yang kompleks, dan menghindari pajak penghasilan. Sebelumnya penelitian menggunakan data arsip (Clotfelter Richardson, 2006) dan data survei (Milliron \& Mainan, 1988; Collins, Milliron, \& Toy, 1992) telah memberikan bukti empiris yang kuat untuk menunjukkan bahwa kompleksitas pajak memiliki hubungan positif dengan kecurangan pajak. Di negara yang rendahnya ketidakpastian dan ambiguitas menyebabkan sedikit hukum dan peraturan yang dirulis. (Hofstede, 1980). Oleh karena itu, sistem pajak di negara-negara tersebut cenderung sederhana karena ada kurang perlu untuk undang-undang dan peraturan perpajakan ditulis. Dalam pengaturan ini, orang cenderung untuk mengenali sistem pajak sebagai sederhana di dan mematuhi undang-undang pajak (Long \& Swingen,1988).

H3: Ketidakpastian penghindaran berpengaruh positif terhadap tingkat kecurangan pajak

\section{Maskulinitas dan Kecurangan Pajak}

Maskulinitas berfokus pada sejauh mana suatu negara memperkuat panutan pekerjaan maskulin tradisional laki-laki prestasi, kontrol, dan kekuasaan. Di negara-negara maskulinitas yang tinggi, orang berusaha untuk pencapaian dalam hal meningkatkan ego, kekayaan, dan pengakuan (Hofstede, 1980, 294). Mereka berfokus pada mengejar kesuksesan materi dalam "dunia tidak adil" (Hofstede, 2001, 321). Sebaliknya, di negara-negara maskulinitas rendah, orang berusaha untuk pencapaian dalam hal kualitas kontak, kehidupan, dan lingkungan (Hofstede, 1980, 294). Mereka fokus pada merawat orang lain, pelestarian memelihara nilai-nilai, dan biasanya melihat dunia sebagai "hanya" tempat yang harus menawarkan kualitas minimum hidup untuk semua orang (Hofstede 2001, 
317-318). Husted (1999, 344) mengklaim bahwa fokus pada kesuksesan materi di negara-negara maskulinitas yang tinggi harus mengarah ke yang lebih besar kesediaan orang untuk berpartisipasi dalam transaksi korup dalam mengejar kesuksesan materi. Dia menemukan hubungan positif antara maskulinitas dan korupsi di negara-negara (Husted 1999, 351). Dengan demikian wajar untuk berteori bahwa penekanan pada keberhasilan materi di negara-negara maskulinitas yang tinggi harus menghasilkan penerimaan yang lebih besar dari kecurangan pajak daripada di rendahnya maskilinitas negara, di mana lebih menekankan ditempatkan pada kualitas kontak, hidup, dan lingkungan. Namun, Tsakumis et al. $(2007,138)$ menunjukkan bahwa kasus juga bisa dibuat untuk hipotesis dalam arah yang berlawanan. Hal ini didukung oleh Hofstede (2001, 319), yang mnemukan korelasi negatif yang signifikan antaramaskulinitas dan Indeks permisif Nasional, menunjukkan bahwa negara-negara maskulinitas tinggi kurang toleran, terutama di berurusan dengan pelanggar hukum (Tsakumis et al., 2007, 138). Berdasarkan uraian diatas maka hipotesis yang diturunkan adalah sbb :

H4: Maskulinitas berpengaruh positif terhadap kecurangan pajak.

\section{Religiusitas dan Tax Evasion}

Definisi religiusitas seperti yang didefinisikan oleh McDaniel dan Burnett (1990) adalah kepercayaan kepada Tuhan disertai dengan komitmen untuk mengikuti prinsip-prinsip yang diyakini ditetapkan oleh Allah. Allport (1950) mengemukakan bahwa agama dianggap peran khas dalam kehidupan individu. Agama dipercaya dapat mengontrol perilaku individu dari sikap yang tidak etis. Seseorang yang memiliki sikap religiusitas yang tinggi cenderung berperilaku etis dann menghindari perilaku kecurangan pajak. Keyakinan agama yang kuat diharapkan mencegah perilaku ilegal melalui perasaan bersalah terutama dalam hal penghindaran pajak (Grasmick, Bursik, \& Cochran, 1991).

H5: Religiusitas berpengaruh negatif terhadap tingkat kecurangan pajak

\section{METODE PENELITIAN}

Populasi dalam penelitian ini adalah Wajib Pajak Orang Pribadi yang terdaftar pada di Kota Pekanbaru. Teknik sampling yang digunakan adalah aksidental sampling. Pemilihan sampel berdasarkan secara kebetulan saja. Setiap wajib pajak yang kebetulan ditemui dan memenuhi kriteria maka dijadikan sebagai sampel. Pengumpulan data dilakukan dengan cara membuat kuisioner yang langsung diserahkan pada responden dan ditunggui pengisiannya. Pada saat itu juga kuisioner dapat kembali

\section{Definisi Operasional Variabel Kecurangan pajak}

Kecurangan pajak menggunakan instrumen yang dikembangkan oleh McGee (2006). Secara umum terdapat 3 (tiga) pandangan dasar mengenai etika kecurangan pajak. Pertama pandangan bahwa kecurangan pajak tidak etis, kedua, kecurangan pajak kadang-kadang etis dan ketiga, kecurangan pajak etis. Variabel diukur dengan menggunakan 15 item pertanyaan yang diukur dengkan skala likert dengan poin $1 \mathrm{~s} / \mathrm{d} 5$ yaitu sangat tidak setuju s/d sangat setuju. Skor rendah 
menunjukkan ketidak setujuan dengan tax evasion dan skor tinggi menunjukkan penerimaan tax evasion

\section{Budaya}

Budaya diukur dengan menggunakan kuisioner dari Hoftede, yang menggunakan 4 dimensi budaya yang terdiri dari jarak kekuasaan terdiri dari 4 item pertanyaan, penghindaran ketidakpastian terdiri dari 5 pertanyaan, individualisme terdiri dari 5 pertanyaan dan maskulinitas terdiri dari 5 pertanyaan, Setiap pertanyaan diukur dengan skala liker 5 yaitu poin $1 \mathrm{~s} / \mathrm{d} 5$, poin $1=$ sangat tidak setuju s/d 5 = sangat setuju.

\section{Religiusitas}

Religiusitas menunjuk pada tingkat keterikatan individu dengan agama. Hal ini menunjukkan bahwa individu telah menghayati dan menginternalisasi ajaran agamanya sehingga berpengaruh dalam segala tindakan dan pandangan hidupnya. Religiusitas dapat dibagi menjadi lima dimensi (Glock, 1962). Pertama, dimensi ideologis, dimana para pengikut agama-agama diharapkan untuk mematuhi set tertentu dari keyakinan. Kedua, dimensi ritualistik - praktek keagamaan tertentu dianut oleh pengikut seperti shalat, puasa dan meditasi. Ketiga, dimensi pengalaman yang menekankan pengalaman religius sebagai indikator tingkat religiusitas. Keempat, dimensi intelektual yang berfokus pada pengetahuan agama digunakan untuk memperkuat satu adalah keyakinan agama. Akhirnya, dimensi konsekuensial mengidentifikasi efek dari kepatuhan terhadap empat dimensi pertama yang individu.panduan untuk berperilaku berdasarkan keyakinan agama, praktek, pengalaman dan pengetahuan. Untuk mengukur religiusitas menggunakan kuisioner yang digunakan oleh Pope dan Mohadali (2010). Pertanyaan terdiri dari 5 item pertanyaan yang diukur dengan skala likert 5 poin. Poin $1=$ Sangat penting sampai dengan $7=$ Sangat tidak Penting.

\section{Metode Analisis}

Dalam penelitian ini, hipotesis diuji dengan menggunakan model regresi linier berganda untuk memperoleh gambaran menyeluruh mengenai pengaruh variabel indipenden terhadap variabel dependen. Sebelum analisis regressi dilakukkan maka dilkukan terlebih dahulu dengan uji asumsi klasik,

Persamaan regresi dalam penelitian ini adalah:

Di mana:

$$
Y=a+\beta_{1} X_{1}+\beta_{2} X_{2}+\beta_{3} X_{3}+\beta_{3} X_{4}+\beta_{3} X_{5} e
$$

$\begin{array}{ll}\mathrm{Y} & =\text { Kecurangan Pajak } \\ \mathrm{a} & =\text { Konstanta } \\ \beta & =\text { Koefisien regresi } \\ \mathrm{X}_{1} & =\text { Jarak Kekuasaan } \\ \mathrm{X}_{2} & =\text { Ketidakpastian Penghindaran } \\ \mathrm{X}_{3} & =\text { Maskulinitas } \\ \mathrm{X}_{4} & =\text { Religiusitas } \\ \mathrm{e} & =\text { Error Term }\end{array}$


Uji $\mathrm{t}$ statistik digunakan untuk melihat pengaruh variabel independen terhadap variabel dependen. Jika t hitung besar dari t tabel dangan sig 5\% ( 1,96 = 1 tailed dan, 1642 tailed) serta $\mathrm{p}$ Value $<5 \%$ maka hipotesis alternatif diterima.

\section{HASIL DAN PEMBAHASAN}

Pada penelitian ini populasi yang digunakan adalah wajib pajak orang pribadi yang terdaftar di KPP Pratama Tampan Pekanbaru. Sebanyak 10o kuisioner disebarkan kepada wajib pajak orang pribadi. Tingkat pengembalian kuesioner dapat digambarkan seperti tabel 1 berikut:

Tabel 1. Tingkat Pengembalian Kuesioner

\begin{tabular}{|l|c|c|}
\hline \multicolumn{1}{|c|}{ Keterangan } & Jumlah & Persentase \\
\hline Kuesioner yang disebar & 100 & $100 \%$ \\
\hline Kuesioner yang kembali & 64 & $64 \%$ \\
\hline Kuesioner yang tidak dapat dianalisis & 4 & $4 \%$ \\
\hline Kuesioner yang dapat dianalisis & 60 & $60 \%$ \\
\hline
\end{tabular}

Sumber: Data primer yang diolah

Berdasarkan table 1 di atas dapat disimpulkan bahwa kuesioner yang disebar sebanyak 100 kuesioner. Kuesioner yang kembali sebanyak 64 buah atau sebesar $64 \%$. Kuesioner yang tidak dapat dianalisis sebanyak 4 buah atau sebesar $4 \%$, sehingga kuesioner yang dapat dianalisis sebanyak 6o atau sebesar $60 \%$.

Karakteristik yang diteliti meliputi jenis kelamin, umur, pendidikan terakhir, agama dan suku. Ringkasan mengenai karakteristik responden dapat dilihat pada tabel 2 berikut:

Tabel 2. Profil Responeden

\begin{tabular}{|l|l|c|c|}
\hline \multirow{2}{*}{ No } & \multicolumn{1}{|c|}{ Keterangan } & \multicolumn{2}{c|}{ Responden } \\
\cline { 3 - 4 } & Jenis Kelamin & Frekuensi & Persentase \\
\hline \multirow{2}{*}{ 1. } & a. Pria & 22 & \\
& b. Wanita & 38 & $37 \%$ \\
\hline \multicolumn{1}{|c|}{ Total } & 60 & $63 \%$ \\
\hline 2. & Usia & 22 & $100 \%$ \\
& a. $\leq 30$ tahun & $37 \%$ \\
& b. 31-40 tahun & 17 & $28 \%$ \\
& c. 41-50 tahun & 12 & $20 \%$ \\
& d. $>50$ & 9 & $9 \%$ \\
\hline \multicolumn{2}{|c|}{ Total } & 60 & $100 \%$ \\
\hline 3. & Pendidikan Terakhir & & $8 \%$ \\
& a. SD - SMA & 5 & $87 \%$ \\
& b. D3-S1 & 52 & $5 \%$ \\
\hline & c. S2 & 3 & $100 \%$ \\
\hline
\end{tabular}




\begin{tabular}{|c|c|c|c|}
\hline \multirow{2}{*}{ No } & \multirow{2}{*}{ Keterangan } & \multicolumn{2}{|c|}{ Responden } \\
\hline & & Frekuensi & Persentase \\
\hline 4. & $\begin{array}{l}\text { Agama } \\
\text { a. Islam } \\
\text { b. Kristen } \\
\text { c. Lainnya }\end{array}$ & $\begin{array}{c}53 \\
5 \\
2\end{array}$ & $\begin{array}{c}88 \% \\
8 \% \\
4 \%\end{array}$ \\
\hline \multicolumn{2}{|l|}{ Total } & 60 & $100 \%$ \\
\hline 5 & $\begin{array}{l}\text { Suku } \\
\text { Minang } \\
\text { Melayu } \\
\text { Jawa } \\
\text { Batak } \\
\text { Betawi }\end{array}$ & $\begin{array}{c}21 \\
16 \\
16 \\
3 \\
4\end{array}$ & $\begin{array}{c}35 \% \\
27 \% \\
27 \% \\
5 \% \\
6 \% \\
\end{array}$ \\
\hline & Total & 60 & $100 \%$ \\
\hline
\end{tabular}

Sumber: Data primer yang diolah

Pada tabel 2 di atas dapat diketahui responden Pria berjumlah 22 orang $(37 \% \%)$, untuk responden perempuan berjumlah 38 orang $(63 \%)$. Responden yang berusia kurang dari 30 tahun berjumlah 22 orang (37\%), untuk responden berusia diantara 26 sampai 30 tahun berjumlah 9 orang $(10,47 \%)$, responden berusia diantara 31 sampai 40 tahun berjumlah 17 orang $(28 \%)$, responden berusia diantara 41 sampai 50 tahun berjumlah 12 orang $(20 \%)$, responden berusia $>50$ tahun berjumlah 9 orang $(9 \%)$.

Untuk responden berdasarkan jenjang pendidikan, didapatkan bahwa responden yang memiliki pendidikan terakhir SD - SMA berjumlah 5 orang (8\%), pendidikan terakhir $\mathrm{D}_{3}$-S1 berjumlah 52 orang (87\%) Sedangkan responden yang jenjang pendidikan S2 berjumlah 3 orang $(5 \%)$.

Responden yang beragama Isalm sebanyak 53 orang (88\%), responden beragama kristen 5 orang (8\%), sedangkan beragama lainnya sebanyak 2 orang (4\%). Responden yang memiliki suku Minang sebanyak 21 orang (35\%), Melayu 16 orang ( $27 \%)$, Jawa 16 orang (27\%), Batak 3 orang (5\%) dan Betawi 4 orang (6\%).

\section{Hasil Statistik Deskriptif}

Statistik deskriptif memberikan gambaran atau deskripsi suatu data yang telah terkumpul yang mencakup perhitungan dari nilai minimum, maksimum, rata-rata (mean), dan standar deviasi (Sugiyono, 2012:206:207). Analisis data pada penelitian ini dilakukan pada 86 orang wajib pajak orang pribadi di Kota Pekanbaru. Statistik penelitian ini dapat dilihat pada tabel 3 sebagai berikut:

Tabel 3. Statistik Deskriptif

\begin{tabular}{|c|c|c|c|c|c|}
\hline & $\mathrm{N}$ & Minimum & Maximum & Mean & $\begin{array}{c}\text { Std. } \\
\text { Deviation }\end{array}$ \\
\hline $\begin{array}{l}\text { Jarak Kekuasaan (Power } \\
\text { Distance ) }\end{array}$ & 60 & 10.00 & 25.00 & 17.8000 & 2.88656 \\
\hline $\begin{array}{l}\text { Penghindaran } \\
\text { ketidakpastian } \\
\text { (Uncertainty Avoidance) }\end{array}$ & 60 & 14.00 & 26.00 & 19.1333 & 2.63912 \\
\hline
\end{tabular}




\begin{tabular}{|llllll|}
\hline Individualisme & 60 & 11.00 & 24.00 & 17.2833 & 3.02022 \\
Maskulinitas & 60 & 13.00 & 25.00 & 18.0667 & 2.64169 \\
Religiusitas & 60 & 23.00 & 40.00 & 32.2667 & 4.66093 \\
Kecurangan Pajak & 60 & 23.00 & 63.00 & 48.3333 & 9.38204 \\
Valid N (listwise) & 60 & & & & \\
\hline
\end{tabular}

Variabel Jarak kekuasaan memiliki nilai minimum 10 dan maximum 25 dengan mean 17,8 dan standar deviasi 2,8. Variabel Penghindaran ketidakpastian memiliki nilai minimum 14 dan maximum 26 dengan mean 19,1 dan standar deviasi 2. Variabel Individualisme memiliki nilai minimum 11 dan maximum 24 dengan mean 17,2 dan standar deviasi 3,02. Variabel Maskulinitas memiliki nilai minimum 13 dan maximum 25 dengan mean 18,06 dan standar deviasi 2,6. Variabel Religiusitas memiliki nilai minimum 23 dan maximum 40 dengan mean 32,26 dan standar deviasi 4,6.Variabel Kecurangan Pajak memiliki nilai minimum 23 dan maximum 63 dengan mean 48,3 dan standar deviasi 9,3.

\section{Hasil Pengujian Validitas Data}

Pengujian validitas data digunakan untuk mengukur sah atau tidak suatu kuesioner. Di mana keseluruhan variabel penelitian terdiri dari 33 pertanyaan yang harus dijawab oleh responden. Uji signifikansi dilakukan dengan membandingkan nilai $r$ hitung dengan $r$ tabel untuk degree of freedom $(\mathrm{df})=\mathrm{n}-2$ dengan alpha o,05, dalam hal ini $n$ adalah jumlah sampel (Ghozali, 2013:53). Dalam penelitian ini $\mathrm{df}=\mathrm{n}-2(60-2)=58$, sehingga didapat $\mathrm{r}$ tabel untuk $\mathrm{df}(58)=0,254$.

Tabel 4. Hasil Uji Validitas Data

\begin{tabular}{|c|c|c|c|c|}
\hline Variabel & Pernyataan & $\begin{array}{c}r \\
\text { hitung }\end{array}$ & $\begin{array}{c}\mathbf{r} \\
\text { table }\end{array}$ & Keputusan \\
\hline \multirow{5}{*}{ Jarak kekuasaan } & $\mathrm{PW}_{1}$ & 0,702 & 0,254 & Valid \\
\hline & $\mathrm{PW}_{2}$ & 0,710 & 0,254 & Valid \\
\hline & $\mathrm{PW}_{3}$ & 0,468 & 0,254 & Valid \\
\hline & $\mathrm{PW}_{4}$ & 0,600 & 0,254 & Valid \\
\hline & $\mathrm{PW}_{5}$ & 0,657 & 0,254 & Valid \\
\hline \multirow{5}{*}{ Individualisme } & IND1 & 0,508 & 0,254 & Valid \\
\hline & IND2 & 0,640 & 0,254 & Valid \\
\hline & $\mathrm{IND}_{3}$ & 0,511 & 0,254 & Valid \\
\hline & $\mathrm{IND}_{4}$ & 0,648 & 0,254 & Valid \\
\hline & $\mathrm{IND}_{5}$ & 0,617 & 0,254 & Valid \\
\hline \multirow{5}{*}{$\begin{array}{l}\text { Penghindaran } \\
\text { ketidakpastian }\end{array}$} & $\mathrm{UA}_{1}$ & 0,646 & 0,254 & Valid \\
\hline & UA2 & 0,597 & 0,254 & Valid \\
\hline & $\mathrm{UA}_{3}$ & 0,429 & 0,254 & Valid \\
\hline & $\mathrm{UA}_{4}$ & 0,585 & 0,254 & Valid \\
\hline & $\mathrm{UA}_{5}$ & 0,698 & 0,254 & Valid \\
\hline \multirow{4}{*}{ Maskulinitas } & MAS1 & 0,561 & 0,254 & Valid \\
\hline & MAS2 & 0,540 & 0,254 & Valid \\
\hline & $\mathrm{MAS}_{3}$ & 0,648 & 0,254 & Valid \\
\hline & $\mathrm{MAS}_{4}$ & 0,578 & 0,254 & Valid \\
\hline
\end{tabular}




\begin{tabular}{|c|c|c|c|c|}
\hline Variabel & Pernyataan & $\begin{array}{c}\mathbf{r} \\
\text { hitung }\end{array}$ & $\begin{array}{c}r \\
\text { table }\end{array}$ & Keputusan \\
\hline & $\mathrm{MAS}_{4}$ & 0,426 & 0,254 & Valid \\
\hline \multirow{8}{*}{ Religiusitas } & $\mathrm{R} 1$ & 0,709 & 0,254 & Valid \\
\hline & $\mathrm{R}_{2}$ & 0,796 & 0,254 & Valid \\
\hline & $\mathrm{R}_{3}$ & 0,764 & 0,254 & Valid \\
\hline & $\mathrm{R}_{4}$ & 0,723 & 0,254 & Valid \\
\hline & $\mathrm{R}_{5}$ & 0,688 & 0,254 & Valid \\
\hline & R6 & 0,479 & 0,254 & Valid \\
\hline & $\mathrm{R}_{7}$ & 0,711 & 0,254 & Valid \\
\hline & $\mathrm{R} 8$ & 0,627 & 0,254 & Valid \\
\hline \multirow{15}{*}{ Kecurangan Pajak } & KP1 & 0,521 & 0,254 & Valid \\
\hline & $\mathrm{KP} 2$ & 0,565 & 0,254 & Valid \\
\hline & $\mathrm{KP}_{3}$ & 0,537 & 0,254 & Valid \\
\hline & $\mathrm{KP}_{4}$ & 0,583 & 0,254 & Valid \\
\hline & $\mathrm{KP}_{5}$ & 0,627 & 0,254 & Valid \\
\hline & KP6 & 0,600 & 0,254 & Valid \\
\hline & $\mathrm{KP}_{7}$ & 0,491 & 0,254 & Valid \\
\hline & KP8 & 0,633 & 0,254 & Valid \\
\hline & $\mathrm{KP}_{9}$ & 0,524 & 0,254 & Valid \\
\hline & KP10 & 0,721 & 0,254 & Valid \\
\hline & KP11 & 0,676 & 0,254 & Valid \\
\hline & KP12 & 0,546 & 0,254 & Valid \\
\hline & KP13 & 0,576 & 0,254 & Valid \\
\hline & KP14 & 0,682 & 0,254 & Valid \\
\hline & $\mathrm{KP}_{15}$ & 0,754 & 0,254 & Valid \\
\hline
\end{tabular}

Tabel 4 diatas menunjukkan bahwa nilai $\mathrm{r}$ hitung untuk masing-masing pernyataan yang memiliki nilai $>\mathrm{r}$ tabel , dapat disimpulkan bahwa semua item valid.

\section{Hasil Pengujian Reliabilitas Data}

Pengujian reliabilitas penelitian ini menggunakan koefisien Cronbach Alpha Variabel ini akan dikatakan realibel jika Cronbach Alpha-nya memiliki nilai lebih besar dari o,6 (Nunnaly, 1981). Begitu juga sebaliknya jika koefisien alpha instrumen lebih rendah dari o,6 maka instrumen tersebut dinyatakan tidak reliabel untuk digunakan dalam penelitian. Pada table 5 di bawah ini akan menerangkan hasil pengujian reliabilitas dari instrumen untuk setiap variabel penelitian.

Tabel 5. Hasil Uji Reabilitas

\begin{tabular}{|l|c|c|}
\hline \multicolumn{1}{|c|}{ Variabel } & $\begin{array}{c}\text { Cronbach's } \\
\text { Alpha }\end{array}$ & Kesimpulan \\
\hline Jarak Kekuasaan (Power distance) & 0,608 & Realibel \\
\hline Individualisme & 0,656 & Realibel \\
\hline
\end{tabular}




\begin{tabular}{|l|c|c|}
\hline \multicolumn{1}{|c|}{ Variabel } & $\begin{array}{c}\text { Cronbach's } \\
\text { Alpha }\end{array}$ & Kesimpulan \\
\hline $\begin{array}{l}\text { Penghindaran ketidakpastian } \\
\text { (Uncertainty Avoidance) }\end{array}$ & 0.608 & Realibel \\
\hline Maskulinitas & 0,655 & Realibel \\
\hline Religiusitas & 0,840 & Reliabel \\
\hline Kecurangan Pajak & 0,875 & Realibel \\
\hline
\end{tabular}

Sumber : Data primer yang diolah

Berdasarkan tabel 5 di atas dapat dilihat bahwa koefisien reliabilitas instrumen semuanya memiliki nilai o,6 Cronbach Alpha > o,6 sehingga dapat disimpulkan bahwa semua instrumen dalam penelitian ini adalah reliabel atau dapat dipercaya.

\section{Hasil Uji Asumsi Klasik Normalitas Data.}

Uji ini bertujuan untuk menguji apakah dalam model regresi, variabel pengganggu atau residual memiliki distribusi normal (Ghozali, 2011:147). Model regresi yang baik adalah data yang terdistribusi normal atau mendekati normal. Metode yang digunakan adalah dengan statistik Kolmogorov Smirnov. Alat uji ini biasa disebut dengan $K$-S yang tersedia dalam program SPSS For Windows. Kriteria yang digunakan dalam tes ini adalah dengan membandingkan antara tingkat signifikansi yang didapat dalam tingkat alpha yang digunakan, dimana data tersebut di katakan berdistribusi normal bila sig > alpha. Hasil uji normalitas dapat dilihat di tabel berikut:

Tabel 6. Hasil Pengujian Normalitas Data

One-Sample Kolmogorov-Smirnov Test

\begin{tabular}{|c|c|c|c|c|c|c|c|}
\hline & & $\begin{array}{l}\text { Power } \\
\text { Distanc } \\
\text { e }\end{array}$ & $\begin{array}{l}\text { Uncertainty } \\
\text { Avoidance }\end{array}$ & $\begin{array}{c}\text { Individualis } \\
\text { me }\end{array}$ & $\begin{array}{c}\text { Maskulinit } \\
\text { as }\end{array}$ & $\left|\begin{array}{c}\text { Kecuranga } \\
\text { n Pajak }\end{array}\right|$ & $\underset{\mathrm{S}}{\text { Religiusita }}$ \\
\hline $\mathrm{N}$ & & 60 & 60 & 60 & 60 & 60 & 60 \\
\hline Normal & Mean & 17.8000 & 19.1333 & 17.0333 & 17.9167 & 48.3333 & 29.5333 \\
\hline Parameters ${ }^{\mathrm{a}, \mathrm{b}}$ & $\begin{array}{l}\text { Std. } \\
\text { Deviation }\end{array}$ & 2.88656 & 2.63912 & 3.37471 & 3.35621 & 9.38204 & 6.61397 \\
\hline Most Extreme & Absolute & .155 & .105 & .113 & .159 & .127 & .145 \\
\hline Differences & Positive & .155 & .105 & .087 & .101 & .059 & .082 \\
\hline & Negative & -.094 & -.068 & -.113 & -.159 & -.127 & -.145 \\
\hline Kolmogorov-S & mirnov Z & 1.204 & .811 & .873 & 1.232 & .982 & 1.122 \\
\hline Asymp. Sig. (2 & -tailed) & .110 & .527 & .431 & .096 & .289 & .162 \\
\hline
\end{tabular}


a. Test distribution is Normal.

b. Calculated from data.

Berdasarkan tabel 6 di atas bahwa besarnya nilai statistik Kolmogorov Smirnov Jika digunakan tingkat signifikansi $\alpha=5 \%$ atau o,05 maka dari tabel diatas dapat dilihat nilai Asymp. Sig. sebesar > 0,05. Dapat disimpulkan bahwa data residual berdistribusi normal.

\section{Heteroskedastisitas}

Homoskedatistisitas (varian sama) merupakan fenomena dimana pada nilai variabel independen tertentu masing-masing kesalahaan (ei) mempunyai nilai varian yang sama. Jika model yang diperoleh ternyata tidak memenuhi asumsi atau fenomena tersebut terjadi heteroskedatisitas. Cara memprediksi ada atau tidak heteroskedatisitas pada suatu model dapat dilihat pada pola gambar Scatterplot model tersebut (Nugroho, 2005:62). Jika membentuk pola tertentu yang teratur, maka regresi mengalami gangguan heteroskedatisitas. Jika diagram pencar tidak membentuk pola atau acak, maka regresi tidak mengalami gangguan heteroskedatisitas (Prastito, 2004:155). Grafik Scatterplot dapat dilihat pada gambar berikut :

\section{Scatterplot}

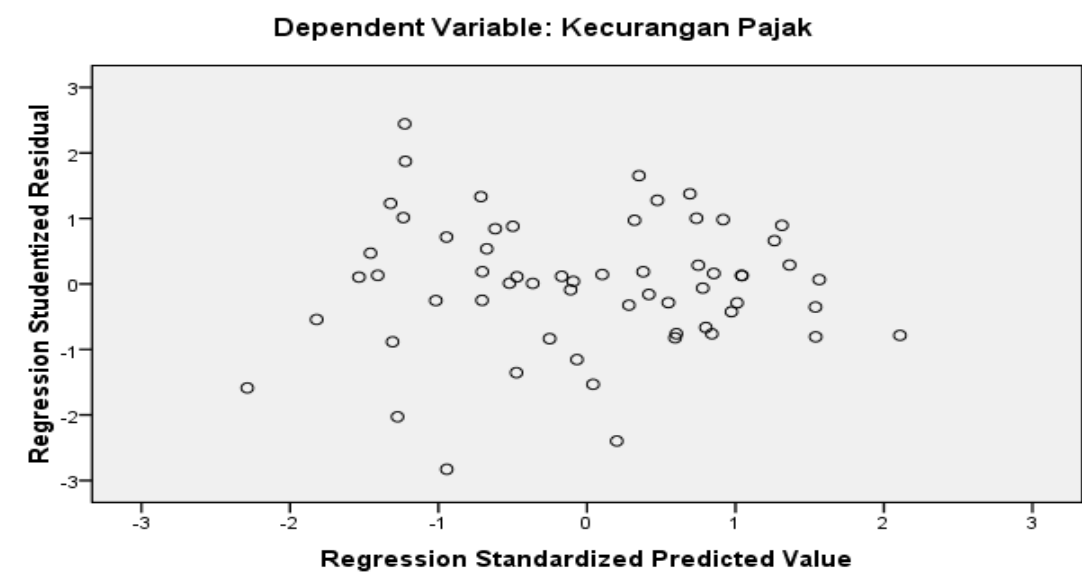

Gambar 1 : Scatterplot

Grafik scatterplot diatas menunjukkan bahwatitik-titik menyebar dan tidak membentuk pola tertentu yang berarti asumsi heteroskedastisitas terpenuhi.

\section{Multikollenearitas}

Multikolinearitas merupakan fenomena adanya korelasi yang sempurna antara satu variabel bebas dengan variabel bebes lainnya. Konsekuensi praktis yang timbul sebagai akibat adanya multikolinearitas ini adalah kesalahaan standar penaksiran semakin besar. Pengujian terhadap ada tidaknya multikolinearitas dilakukan dengan mengamati besaran variance inflation factor (VIF) dan tolerance, 
model dikatakan bebas multikolinearitas jika VIF $<10$, sedangkan nilai tolerance disekitar 1.

Tabel 7. Hasil Pengujian Multikollenearitas

\begin{tabular}{|c|c|c|c|}
\hline & & \multicolumn{2}{|c|}{ Collinearity Statistics } \\
\hline \multicolumn{2}{|c|}{ Model } & Tolerance & VIF \\
\hline \multirow[t]{6}{*}{1} & (Constant) & & \\
\hline & Power Distance & .930 & 1.075 \\
\hline & Uncertainty Avoidance & .782 & 1.278 \\
\hline & Individualisme & .864 & 1.157 \\
\hline & Maskulinitas & .829 & 1.207 \\
\hline & Religiusitas & .883 & 1.132 \\
\hline
\end{tabular}

Sumber : Data primer yang diolah

Tabel di atas menunjukkan nilai Tolerance mendekati 1 dan VIF <10 yang berarti asumsi moltikolenearitas terpenuhi yaitu tidak terdapat hubungan antara variabel indipenden.

\section{Hasil Pengujian Hipotesis}

Hasil pengujian hipotesis dapat dilihat pada tabel 8 berikut :

Tabel 8. Hasil Analisis Regresi Berganda

\begin{tabular}{|c|c|c|c|c|c|c|}
\hline \multirow{2}{*}{\multicolumn{2}{|c|}{ Model }} & \multicolumn{2}{|c|}{ Unstandardized Coefficients } & \multirow{2}{*}{$\begin{array}{c}\begin{array}{c}\text { Standardized } \\
\text { Coefficients }\end{array} \\
\text { Beta }\end{array}$} & \multirow[b]{2}{*}{$\mathrm{t}$} & \multirow[b]{2}{*}{ Sig. } \\
\hline & & B & Std. Error & & & \\
\hline \multirow[t]{6}{*}{1} & (Constant) & 22.053 & 9.489 & & 2.324 & .024 \\
\hline & $\begin{array}{l}\text { Jarak kekuasaan } \\
\text { (Power Distance) }\end{array}$ & 1.044 & .329 & .321 & 3.173 & .002 \\
\hline & $\begin{array}{l}\text { Penghindaran } \\
\text { ketidakpastian } \\
\text { (Uncertainty } \\
\text { Avoidance) }\end{array}$ & .052 & .392 & .015 & .132 & .895 \\
\hline & Individualisme & .358 & .292 & .129 & 1.226 & .226 \\
\hline & Maskulinitas & .971 & .300 & .347 & 3.240 & .002 \\
\hline & Religiusitas & -.569 & .147 & -.401 & -3.859 & .000 \\
\hline
\end{tabular}

a. Dependent Variable: Kecurangan Pajak

\section{Hasil Pengujian Hipotesis 1}

Berdasarkan dari tabel 8, maka dapat dilihat nilai t 3,173 > titik kritis 1,645 (1-tailed) dengan sig 0,002<0,005. Dapat disimpulkan bahwa jarak kekuasan berpengaruh terhadap kecurangan pajak. Hubungan bersifat positif dengan nilai korelasi 1,04 yang berarti semakin tinggi jarak kekuasaan maka makin tinggi 
tingkat kecurangan pajak wajib pajak orang pribadi pada KPP Pratama Tampan Pekanbaru.

Hasil penelitian ini mendukung penemuan Song \& Yarbrough (1978) yang menyatakan bahwa pada negara-negara jarak kekuasaan rendah di negara-negara tersebut kekayaan hampir merata dengan sistem perpajakan yang adil, artinya jika jarak kekuasaan tinggi maka kekayaan pada masyarakat tidak merata. Masyarakat yang merasa tidak adil cedrung untuk melakukan kecurangan pajak untuk menghindari pengeluaran yang besar.

\section{Hasil Pengujian Hipotesis 2}

Berdasarkan dari tabel 8, maka dapat dilihat nilai t hitung 1,226 <1,64 ( 1 tailed) dan sig 0,226>0,05 yang berarti hipotesis dapat ditolak. Hasil penelitian menunjukkan individualisme tidak berpengaruh terhadap kecurangan pajak. Hasil ini tidak mendukung Hofstede (1980) dan (Sandford, 2000) yang menyatakan pada negara yang memiliki individualisme tinggi dengan prosedur yang merata menyebabkan rendahnya kecurangan pajak. Namun dalam penelitian ini individualisme tidak mepengaruhi kecurangan pajak. Hal ini menunjukkan bahwa individualisme yang dirasakan oleh wajib tidak mempengaruhi sikap mereka.

\section{Hasil Pengujian Hipotesis 3}

Berdasarkan dari tabel 8, maka dapat dilihat nilai t hitung $0,132<$ titik kritis 1,64 (1 tailed) dan sig 0,89 > 0,05 maka dapat disimpulkan ketidakpastian tidak berpengaruh terhadap kecurangan pajak. Hasil penelitian ini tidak konsisten dengan penelitian Clotfelter \& Richardson (2006) dan Milliron \& Mainan (1988); Collins, Milliron, \& Toy (1992) yang menunjukkan bahwa kompleksitas pajak memiliki hubungan positif dengan kecurangan pajak, yang berarti tingginya ketidakpastian pajak menunjukkan tingginya ambiguitas yang menyebabkan kecendrungan orang melakukan kecurangan pajak lebih tinggi.

Di Pekanbaru khususnya KPP Pratama Tampan pengurusan pajak tidaklah begitu rumit. Apalagi responden dalam penelitian termasuk wajib pajak orang pribadi yang berstatus sebagai karyawan yang pengurusan pajaknya biasanya langsung diurus secara kolektif oleh perusahaan sehingga mereka tidak merasakan kerumitan pengurusan pajak.

\section{Hasil Pengujian Hipotesis 4}

Berdasarkan dari tabel 8, maka dapat dilihat nilai t hitung 3,240 > titik kritis 1,64 ( 1 tailed) dan sig 0,002 < 0,005 yang berarti hipotesis diterima. Hasil penelitian menunjukkan nilai korelasi positif yang berarti semakin tinggi maskulinitas maka semakin tinggi tingkat kecurangan pajak. Dapat disimpulkan bahwa meningkatnya maskulinitas maka akan meningkatkan kecurangan pajak wajib pajak orang pribadi pada KPP Pratama Tampan Pekanbaru. Hasil penelitian ini mendukung Hosfted (1980) bahwa di negara-negara maskulinitas yang tinggi, orang berusaha untuk pencapaian dalam hal meningkatkan ego, kekayaan, dan pengakuan dan mereka berfokus pada mengejar kesuksesan materi yang menyebabkan kecendrungan untuk melakukan kecurangan juga lebih tinggi. Hasil ini juga mendukung penelitian Hofstede (2001) yang menemukan korelasi negatif yang signifikan antara maskulinitas dan Indeks permisif Nasional, menunjukkan 
bahwa negara-negara maskulinitas tinggi kurang toleran, terutama dengan pelanggar hukum (Tsakumis et al., 2007).

\section{Hasil Pengujian Hipotesis 5}

Berdasarkan dari tabel 8, maka dapat dilihat nilai t -3,859 > titik kritis 1,64 ( 1 tailed) dengan signifikansi o,ooo < 0,05 yang berarti hipotesis diterima. Hasil analisis menunjukkan korelasi negatif sebesar -0,569 yang berarti semakin tinggi religiusitas maka kecurangan pajak wajib pajak orang pribadi di KPP Pratama Tampan Pekanbaru makin rendah. Hasil penelitian ini mendukung Grasmick, Bursik, \& Cochran (1991) bahwa keyakinan yang kuat pada agama mengurangi sikap untuk melakukan kecurangan pajak.

\section{SIMPULAN}

Berdasarkan data yang diperoleh dan hasil pengujian yang telah dilakukan dengan menggunakan model regresi linier berganda, maka dapat disimpulkan bahwa Jarak kekuasan berpengaruh positif terhadap kecurangan pajak. Semakin tinggi jarak kekuasaan maka kecurangan pajak juga akan semakin tinggi pada wajib pajak orang pribadi yang terdaftar pada KPP Pratama Tampan Pekanbaru. Individualisme tidak berpengaruh terhadap kecurangan pajak wajib pajak yang terdaftar pada KPP Pratama Tampan. Hal ini menunjukkan bahwa individualisme yang dirasakan oleh wajib tidak mempengaruhi sikap mereka. Ketidakpastian tidak berpengaruh terhadap kecurangan pajak wajib pajak orang pribadi pada KPP Pratama Tampan Pekanbaru. Maskulinitas berpengaruh positif terhadap kecurangan pajak. Semakin tinggi maskulinitas maka semakin tinggi tingkat kecurangan pajak wajib pajak pada KPP Pratama Tampan Pekanbaru. Religiusitas berpengaruh negatif terhadap kecurangan pajak. Semakin tinggi religiusitas maka kecurangan pajak makin rendah pada wajib pajak orang pribadi yang terdaftar pada KPP Pratama Tampan Pekanbaru. Hasil penelitian ini mendukung Grasmick, Bursik, \& Cochran (1991) bahwa keyakinan yang kuat pada agama mengurangi sikap untuk melakukan kecurangan pajak.

\section{PUSTAKA ACUAN}

Alm, J., \& Torgler, B. (2006). Culture differences and tax morale in the United States and in Europe. Journal of Economic Psychology, 27, 224-246.

Andreoni, J., Erard, B., \& Feinstein, J. (1998). Tax compliance. Journal of Economic Literature, 36, 818-86o.

Baskerville, R. F. (2003). Hofstede never studied culture. Accounting, Organizations and Society, 28, 1-14.

Brunetti, A., \&Weder, B. (2003). A free press is bad news for corruption. Journal of Public Economics, 87, 1801-1824.

Bird, R. (1992). Tax policy and economic development. Baltimore: The Johns Hopkins University Press.

Chan, C.W., Troutman, C. S., \& O'Bryan, D. (200o). An expanded model of taxpayer compliance: Empirical evidence from the United States and Hong Kong.

Journal of International Accounting, Auditing and Taxation, 9, 83-103. 
Clotfelter, C. (1983). Tax evasion and tax rates: An analysis of individual returns. The Review of Economics and Statistics, 65, 363-373.

Coleman, C., \& Freeman, L. (1997). Cultural foundations of taxpayer attitudes to voluntary compliance. Australian Tax Forum, 13, 311-336.

Collins, J. H., Milliron, V. C., \& Toy, D. R. (1992). Determinants of tax compliance: A contingency approach. Journal of the American Taxation Association, 14, $1-29$.

De Mooij, M. (1998). Global marketing and advertising: Understanding cultural paradoxes. In Thousand Oaks. CA: Sage Publications.

De Mooij, M. (1998b). Masculinity/femininity and consumer behavior. In G. Hofstede \& Associates (Eds.), Masculinity and femininity: The taboo dimension of national cultures (pp. 55-73). Thousand Oaks, CA: Sage Publications.

De Mooij, M. (2001). Convergence-divergence. Unpublished doctoral dissertation, Universidad de Navarra.

De Soto, H. (200o). The mystery of capital: Why capitalism triumphs in the west and fails everywhere else. New York, NY: Basic Books.

Doupnik, T. S., \& Tsakumis, G. T. (2004). A critical review of tests of Gray's theory of cultural relevance and suggestions for future research. Journal of Accounting Literature, 23, 1-48.

Eigen, P. (2002). Measuring and combating corruption. Journal of Policy Reform, 5, 187-201.

Feinstein, J. S. (1991). An econometric analysis of income tax evasion and its detection. RAND Journal of Economics, 22, 14-35.

Feld, L. P., \& Frey, B. S. (2002). Trust breeds trust: How taxpayers are treated. Economics of Governance, 3, 87-99.

Fisman, R., \& Gatti, R. (2002). Decentralization and corruption: Evidence across countries. Journal of Public Economics, 83, 325-345.

Frey, B. S., \&Weck, H. (1983). Estimating the shadow economy: A 'naïve' approach. Oxford Economic Papers, 35, 23-44.

Grasmick, H. G., Bursik, R. J., \& Cochran, J. K. (1991). Render unto Caesar what is Caesar's: Religiosity and taxpayers' inclinations to cheat. The Sociological Quarterly, 32, 251-266.

Hair, J. F., Anderson, R. E., Tatham, R. L., \& Black,W. C. (1998). Multivariate data analysis (5th ed.). Upper Saddle River, NJ: Prentice Hall.

Hite, A., \& Roberts, M. L. (1992). An analysis of tax reform based on taxpayers' perceptions of fairness and self-interest. Advances in Taxation, 4, 115-137.

Hofstede, G. H. (1980). Cultures consequences: International differences in workrelated values. In Beverly Hills. CA: Sage Publications.

Hofstede, G. H. (1983). Dimensions of national cultures in fifty countries and three regions. In J. B. Deregowski, S. Dziurawice, \& R. C. Annis (Eds.), Expiscations in cross-cultural psychology (pp. 335-355). Lisse, The Netherlands: Swets and Zeitlinger.

Hofstede, G. H. (2001). Cultures consequences: Comparing values, behaviors, institutions and organizations across nations (2nd ed.). London: Sage Publications.

Hofstede, G. H., \& Bond, M. H. (1988). The Confucius connection: From cultural roots to economic growth. Organizational Dynamics, 5-21. 
Jackson, B. R., \& Milliron, V. C. (1986). Tax compliance research: Findings, problems and prospects. Journal of Accounting Literature, 5, 125-165.

Long, S., \& Swingen, J. (1991). Taxpayer compliance: Setting new agendas for research. Law and Society Review, 25, 637-683.

Riahi-Belkaoiu, A. (2004). Relationship between tax compliance internationally and selected determinants of tax morale. Journal of International Accounting, Auditing and Taxation, 13, 135-143.

Richardson, G. (2006). Determinants of tax evasion: A cross-country investigation. Journal of International Accounting, Auditing and Taxation, 15, 150-169.

Richardson, G. (2007). The influence of culture on tax systems internationally: A theoretical and empirical analysis. Journal of International Accounting

Research, 6, 57-79.

Schuler, R. S., \& Rogovsky, N. (1998). Understanding compensation practice variations across firms: The impact of national culture. Journal of International Business Studies, 29, 159-

Tittle, C. (1980). Sanctions and social deviance: The question of deterrence. New York, NY: Praeger.

Tittle, C., \&Welch, M. (1983). Religiosity and deviance: Towards a contingency theory of constraining effect. Social Forces, 61, 653-682.

Tsakumis, G. T., Curatola, A. P., \& Porcano, T. M. (2007). The relation between national cultural dimensions and tax evasion. Journal of International Accounting, Auditing and Taxation, 16, 131-147.

Torgler, B. 2006. The Importance of Faith: Tax Morale and Religiosity. Journal of Economic Behavior \& Organization, 61(1), 81-109.

Pope J dan Mohdali R .2010. The role of religiosity in tax morale and tax compliance. Australian Tax Forum : 565-592 